\author{
ARTIGO \\ dO $\underline{\text { https://doi.org/10.22481/praxisedu.v16i42.6430 }}$
}

\title{
EGRESSOS DE UM CURSO DE MESTRADO EM EDUCAÇÃO: PERFIL E DESENVOLVIMENTO PROFISSIONAL DOCENTE
}

\author{
EGRESS FROM A MASTER EDUCATION COURSE: PROFILE, AND TEACHING \\ PROFESSIONAL DEVELOPMENT
}

\section{EGRESOS DE UN CURSO MASTER EN EDUCACIÓN: PERFIL Y DESARROLLO PROFESIONAL}

\section{Susély Aparecida Fonseca Gonçalves}

Universidade de Uberaba - Brasil

Marilene Ribeiro Resende

Universidade de Uberaba - Brasil

\begin{abstract}
Resumo: Este artigo traz resultados de uma pesquisa, de abordagem mista, que buscou traçar o perfil e investigar as contribuições do curso de Mestrado em Educação de uma Universidade, situada na região do Triângulo Mineiro - MG, para o desenvolvimento profissional docente dos egressos de 2003 a 2015, que, ao ingressar no curso, atuavam no ensino superior. O corpus de análise resultou de questionário respondido por 44 desses egressos, e de entrevista semiestruturada realizada com oito deles. Fundamenta-se em autores que discutem a pós-graduação em educação (Severino, 2006 e 2009; Cury, 2005); em pesquisadores que tratam o desenvolvimento profissional docente (Marcelo Garcia, 1999; Cunha, 2010, 2017). Em sua maioria, os egressos da IES pesquisada construíram a sua trajetória de formação e de atuação em instituições privadas de ensino superior. Têm a necessidade de aprimoramento profissional e o desejo de ascensão na carreira, motivos principais para a busca de um curso de mestrado, porém poucos contaram com bolsas de estudo, com a liberação das atividades profissionais ou redução de carga horária para a realização do curso. A contribuição mais importante para o desenvolvimento profissional docente, segundo os participantes, foi o aprofundamento de conhecimento. A preparação para a atividade de pesquisa foi assinalada pela maioria, mas não é a mais significativa, pois nem sempre esses egressos encontram ambiente favorável para essa atividade nas IES, onde atuam.
\end{abstract}

Palavras chave: Egresso. Pós-Graduação. Educação.

\begin{abstract}
This article presents the results of a research with mixed approach, which sought to profile and investigate the contributions of the Master's degree course of a University located in the region of Triangulo Mineiro - MG, for the formation of graduates from 2003 to 2015, who worked in teaching. higher. The corpus of analysis resulted from a questionnaire answered by 44 of these graduates and a semi-structured interview with eight of them. It is based on authors who discuss postgraduate education (Severino, 2006 and 2009; Cury, 2005); in
\end{abstract}


researchers who deal with teacher professional development (Marcelo Garcia, 1999; Cunha, 2010, 2017). Most of the graduates of the researched institution built their trajectory of formation and performance in private institutions of higher education. They have the need for professional improvement and the desire for career advancement, which are the main reasons for pursuing a master's degree, but few had scholarships, the release of professional activities or reduction of workload to complete the course. The most important contribution was the deepening of knowledge. The majority indicated the preparation for the research activity, but it is not the most significant, since these graduates do not always find a favorable environment for this activity in private institution where they work.

Keywords: Egress. Postgraduate studies. Education.

Resumen: Este artículo presenta los resultados de una investigación con enfoque mixto, que buscó perfilar e investigar las contribuciones del curso de maestría de una universidad ubicada en la región de Triangulo Mineiro - MG, para el desarrollo profesional de egresos de 2003 a 2015, que , al ingresar, trabajaron en la educación superior. El corpus de análisis resultó de un cuestionario respondido por 44 de estos graduados, y de una entrevista semiestructurada con ocho de ellos. Se basa en autores que discuten la educación de posgrado (Severino, 2006 y 2009; Cury, 2005); en investigadores que se ocupan del desarrollo profesional docente (Marcelo García, 1999; Cunha, 2010, 2017). La mayoría de los graduados del institución investigado construyeron su trayectoria de formación y desempeño en instituciones privadas de educación superior. Tienen la necesidad de mejorar profesionalmente y el deseo de avanzar en su carrera, que son las principales razones para obtener un título de maestría, pero pocos tenían becas, con el lanzamiento de actividades profesionales o la reducción de la carga de trabajo para completar el curso. La contribución más importante al desarrollo profesional docente, según los participantes, fue la profundización del conocimiento. La preparación para la actividad de investigación fue indicada por la mayoría, pero no es la más significativa, ya que estos graduados no siempre encuentran un ambiente favorable para esta actividad en las instituciónes, donde trabajan.

Palabras clave: Egreso. Posgraduación. Educación.

\section{Introdução}

A pós-graduação, no Brasil, começa a se estabelecer no século XX. Segundo Santos e Azevedo (2009), institucionalmente, na década de 1960. A Lei n. 4.024/61, que fixou as Diretrizes e Bases da Educação Nacional - LDB, previa, no Art. 69, que as instituições de ensino superior poderiam ofertar cursos de graduação, cursos de especialização, de aperfeiçoamento, de especialização e de extensão, e cursos de pós-graduação a candidatos que tivessem recebido o diploma de graduação. Entretanto um marco regulatório importante foi o Parecer nº. 977/65 da Câmara de Ensino Superior do Conselho Federal de Educação, hoje, Conselho Nacional de Educação, cujo objetivo era esclarecer a natureza e os objetivos da pósgraduação no país, definindo sua estrutura e funcionamento. Esse Parecer "foi e ainda continua 
sendo a referência sistemática para a organização e implementação da pós-graduação brasileira". (CURY, 2005, p. 07).

Esse documento legal estabeleceu a natureza dos cursos de pós-graduação lato sensu e stricto sensu, a qual ainda permanece - os cursos lato sensu compreendem programas de especialização, com duração mínima de 360 horas, e os stricto sensu abrangem os programas de mestrado e doutorado, ofertados por instituições de ensino superior.

De acordo com Severino (2006), a Pós-Graduação vem contribuindo para um melhor conhecimento da realidade brasileira e o avanço das ciências e das tecnologias em todos os campos, tendo grande contribuição na qualificação dos profissionais.

Por sua vez, a pós-graduação em educação teve o seu primeiro mestrado aprovado no final de 1965, na Pontifícia Universidade Católica do Rio de Janeiro (PUC-Rio). Passados mais de 50 anos de sua criação, é, hoje (2019), uma das áreas mais expressivas da pós-graduação no país. Segundo dados da Coordenação de Aperfeiçoamento de Pessoal de Nível Superior CAPES, constantes da Plataforma Sucupira ${ }^{1}$ (2019), é, em número de programas e cursos, uma das maiores, contando com 186 programas e 275 cursos, sendo 136 de Mestrado Acadêmico, 89 de Doutorado, 49 de Mestrado Profissional e um de Doutorado Profissional. É suplantada, apenas, por duas áreas de avaliação da CAPES, a Interdisciplinar e a de Ciências Agrárias I. Essa realidade impõe a preocupação com as contribuições desse campo para o avanço do conhecimento ligado à área, por meio da pesquisa e da produção e para a formação de profissionais para atuar na educação em todos os níveis.

Nas regiões do Triângulo Mineiro e Alto Paranaíba, em Minas Gerais, o primeiro Programa de Pós-Graduação em Educação - PPGE foi criado em 1988, na Universidade Federal de Uberlândia - UFU, começando as suas atividades em 1990, oferecendo o curso de Mestrado. Em 2005, foi autorizado e recomendado pela CAPES o curso de doutorado, com o ingresso da primeira turma em 2006.

Posteriormente, na Universidade de Uberaba, em 1999, foi criado o PPGE-UNIUBE, recomendado pela CAPES, em 2004, para a oferta do curso de Mestrado. Em 2015, teve o curso de doutorado aprovado, com início da primeira turma, em março de 2016. Outros cursos foram criados, como o de Mestrado em Educação na Universidade Federal do Triângulo Mineiro UFTM, em 2012, e o curso de Mestrado Profissional em Educação Profissional e Tecnológica, no Instituto Federal do Triângulo Mineiro - IFTM, em 2018.

\footnotetext{
${ }^{1}$ Disponível em: https://sucupira.capes.gov.br/sucupira/public/consultas/coleta/programa/quantitativos/quantitativoAreaAvaliacao .jsf;jsessionid=IpC19tcuSCVdbQWNHKsjYjWE.sucupira-213. Acesso em dez.2019.
} 
Apesar do número significativo de titulados pelo PPGE da Instituição pesquisada, no período de 2003 a 2015, 210 dissertações, não há pesquisa que tenha investigado, de forma sistemática, o perfil, as motivações e as contribuições que esse Programa proporcionou aos egressos. Evidente que, quando um programa em pós-graduação atinge certo nível de maturidade, é importante verificar e analisar as suas contribuições. $\mathrm{O}$ acompanhamento de egressos é, inclusive, um critério de avaliação da CAPES, que busca garantir a qualidade dos cursos de pós-graduação. Os cursos existem para oportunizar a formação do pesquisador e do docente. Assim, a inserção social do Programa muito depende de como os egressos estão se desenvolvendo profissionalmente.

A pesquisa que, em parte, é retratada neste artigo investigou o perfil e as contribuições do Programa para a formação e o desenvolvimento profissional docente dos egressos, entre os anos de 2003 (primeiras defesas) e 2015 (10 anos do credenciamento), do curso de Mestrado. A pesquisa tratou separadamente os egressos que, quando ingressantes no curso, atuavam na educação básica, e os que atuavam no ensino superior, pois partiu-se da hipótese de que as contribuições poderiam ser diferentes. Este artigo apresenta os resultados desse segundo grupo.

\section{Aspectos metodológicos}

Levando-se em consideração o objetivo, a pesquisa teve abordagem quali-quantitativa ou mista. Esse tipo de pesquisa é considerado por Gray (2012, p. 163) como aquele "que inclui, pelo menos, um método quantitativo e um qualitativo, onde nenhum deles está inerentemente ligado a qualquer paradigma de investigação específico." Segundo o autor, embora as duas pesquisas sejam distintas, nos últimos tempos, alguns pesquisadores têm utilizado a abordagem mista em uma única pesquisa, aproveitando os pontos fortes de cada uma. O uso da abordagem mista permite a obtenção de "uma visão mais rica e contextual do fenômeno que está sendo pesquisado". (GRAY, 2012, p.167).

A questão da quantificação se mostra presente na pesquisa relatada, na elaboração do questionário, na seleção da amostra para a entrevista, na coleta e análise de dados e nos resultados obtidos, entretanto, sem perder de vista os princípios da pesquisa qualitativa.

A pesquisa de campo foi realizada por meio de questionário e de entrevista semiestruturada, gravada em áudio e depois transcrita. Os participantes são os egressos do PPGE da IES investigada, do período de 2003 a 2015, que atuavam no ensino superior e cuja dissertação está disponível na Biblioteca Central da IES. Primeiramente foi encaminhado o 
questionário via online a todos os egressos do curso, concluintes no período de 2003, primeira turma, a 2015, que atuavam no ensino superior, quando ingressaram no curso. Como o retorno não atingiu o mínimo de $80 \%$ do total de concluintes, a aplicação foi realizada com o instrumento impresso, pela própria pesquisadora, atingindo 44 respondentes. As entrevistas foram realizadas com, aproximadamente, $20 \%$ desses, portanto, realizadas com oito participantes, selecionados aleatoriamente, de forma estratificada, dentre os que se dispuseram a participar dessa etapa, ao responder o questionário. A amostra dos participantes da entrevista é do tipo aleatória, dado que todos os participantes tiveram igual chance de serem selecionados. É considerada estratificada, pois foram estabelecidos dois estratos para a classificação dos participantes: ser docente da IES e não ser docente da IES. Para garantir a aleatoriedade, foi utilizada uma Tabela de Números Aleatórios. Como o total de respondentes do questionário foi de 44, sendo 19 docentes da IES e 25 não docentes, decidiu-se estabelecer que, dentre os oito egressos a serem entrevistados, quatro seriam de um grupo e quatro, do outro.

No que concerne à análise, os dados advindos do questionário foram tabulados em planilhas do Excel e calculadas algumas medidas estatísticas, tais como frequências percentuais e médias. Os dados oriundos das entrevistas foram submetidos à análise de conteúdo, que permitiu fazer inferências a partir do conteúdo das mensagens. Por meio da análise de conteúdo, podemos “caminhar na descoberta do que está por trás dos conteúdos manifestos, indo além das aparências do que está sendo comunicado". (MINAYO, 2015, p. 84).

Como se trata de projeto envolvendo seres humanos, esse foi submetido ao Comitê de Ética em Pesquisa - CEP, para apreciação e parecer. Após aprovação do CEP, com CAAE nº. 57487116.0.0000.5145, os esclarecimentos acerca da pesquisa foram realizados e, em seguida, a assinatura do Termo de Consentimento Livre e Esclarecido - TCLE, dando aos egressos a liberdade de participarem ou não.

\section{A formação e o desenvolvimento profissional docente - a docência e a pesquisa}

Os programas de pós-graduação em Educação, de modo geral, têm como um de seus objetivos a formação de pesquisadores e de docentes para os diferentes níveis da educação nacional, de modo especial, para o ensino superior. A formação de professores para esse nível em cursos de pós-graduação, prioritariamente em programas de mestrado e doutorado, está prevista na Lei de Diretrizes e Bases da Educação Nacional - LDB/96, em seu Artigo 44. 
$\mathrm{Na}$ universidade brasileira, ensino, pesquisa e extensão constituem o seu tripé e se articulam organicamente. Entretanto, Severino (2009) atribui à pesquisa um lugar de destaque, ao afirmar que o ensino e a extensão supõem construção de conhecimento, o que exige pesquisa:

Na universidade, ensino, pesquisa e extensão efetivamente se articulam, mas a partir da pesquisa, ou seja, só se aprende, só se ensina, pesquisando; só se presta serviços à comunidade, se tais serviços nascerem e se nutrirem da pesquisa. Impõe-se partir de uma equação, de acordo com a qual educar (ensinar e aprender) significa conhecer; e conhecer, por sua vez, significa construir o objeto; mas construir o objeto significa pesquisar. Por isso mesmo, também na universidade, a aprendizagem, a docência e o ensino só serão significativos, se forem sustentados por permanente atividade de construção do conhecimento. (SEVERINO, 2009, p. 121).

A docência é uma atividade que, geralmente, aparece ligada ao ministrar aula, porém essa é uma visão restrita, pois pode ser compreendida como trabalho do professor em diferentes espaços educacionais. Ibiapina (2004, p. 332) conceitua a docência como "atividade em que o professor mobiliza e articula as atitudes de colaboração, reflexão, pesquisa e crítica em contextos formativos, com motivo e objetivo de mediar aprendizagens".

Uma das atividades da docência é a atividade de pesquisa e precisa se apoiar em pressupostos epistemológicos, metodologias específicas e técnicas pertinentes. Segundo Severino (2009, p. 123),

Pesquisar assume, então, o sentido de conhecer como processo de construção do objeto, apoiando-se em premissas epistêmicas e em procedimentos metodológicos e técnicos, a partir das fontes primárias do próprio objeto. Trata-se, na verdade, de sua reconstrução, graças à decomposição e à recomposição dos elementos que o integram, num processo simultâneo e alternado de operações de análise e síntese.

Nesse sentido, o autor argumenta que o professor universitário não se furta à atividade de pesquisa e defende uma estreita vinculação entre o ensino e a pesquisa. Argumenta que a aprendizagem supõe a apropriação de conhecimentos em seus processos específicos, e o fundamental é o processo e não apenas o produto. Disso decorre a importância da pesquisa, como processo de construção dos objetos, de modo sistemático e metódico. Alerta que isso não significa querer transformar a universidade em instituição de pesquisa, mas defender a postura investigativa na docência.

No que concerne à formação de professores, Cunha (2010) afirma que ela se constitui em um processo de desenvolvimento profissional emancipatório e autônomo, e não ocorre numa trajetória linear, mas, sim, num processo de evolução, continuidade e percurso profissional, no qual diversos fatores, sociais, familiares e pessoais atuam. 
O desenvolvimento profissional, segundo Marcelo García (1999), apoiando-se em Howey (1985), inclui várias dimensões: o desenvolvimento pedagógico, o conhecimento e a compreensão de si mesmo, o desenvolvimento cognitivo, o desenvolvimento teórico, o desenvolvimento profissional e o desenvolvimento da carreira. Essas são as dimensões intrínsecas do desenvolvimento profissional. Do mesmo modo, no entendimento desse autor, a compreensão do desenvolvimento profissional docente articula-se a outras instâncias de desenvolvimento, sem as quais perde o sentido. São elas: o desenvolvimento da escola, do currículo, do ensino e da profissionalidade. Essas dimensões elencadas são consideradas como as dimensões externas do desenvolvimento profissional dos docentes.

Por fim, segundo Soares e Cunha (2010), o desenvolvimento profissional projeta-se por uma disposição interna e por uma postura permanente de crescimento pessoal e profissional, juntamente com a disposição de reflexão sobre as práticas, crenças e atitudes, tanto individuais como coletivas.

Cabe destacar que muitos dos alunos que buscam os cursos de pós-graduação em educação não são licenciados e procuram nesses a formação para exercerem a docência. Nesse sentido, concordamos com Araújo e Araújo (2019, p. 386), quando sugerem que

[...] os programas de pós-graduação em educação e em ensino ofertem disciplinas que tenham por foco discutir a formação de professores, tendo em vista que muitos desses pós-graduandos serão professores da educação superior e, consequentemente, possíveis formadores de professores.

A formação para a docência em cursos de pós-graduação é, inclusive, prevista na LDB/96, quando trata a formação do professor universitário. Sendo assim, os cursos de pós-graduação em educação não podem se furtar a esse compromisso.

\section{Perfil dos egressos, formação e atividade profissional}

No delineamento do perfil do egresso, buscou-se conhecer o participante da pesquisa suas características, sua formação na graduação e na pós-graduação, exercício da docência, antes e depois do mestrado. Esses dados foram coletados por meio do questionário, que tinha quatro blocos: perfil, formação, atividades profissionais (anteriores e posteriores ao mestrado), pós-graduação em educação (contribuições).

No que concerne ao sexo dos participantes, observou-se um número maior de egressos do sexo feminino (68\%). O ingresso das mulheres na Pós-graduação em percentual superior é consequência da maior presença, histórica, das mulheres na área da Educação. De acordo com 
Placco e Souza (2014, p. 12), “os homens procuram assumir espaços ainda demarcados para a vivência de suas masculinidades", tais como direção, coordenação e supervisão, ou seja, gestão escolar.

Dos egressos pesquisados, no momento em que cursaram o Mestrado em Educação, 45\% (20) trabalhavam na própria IES pesquisada, e os demais exerciam suas atividades profissionais em 13 Instituições situadas no Triângulo Mineiro e Alto Paranaíba, nas cidades de Araxá, Uberlândia, Uberaba, Patrocínio, Patos de Minas e Ituiutaba, além de outras, em menor número, fora dessas regiões.

Referentemente às IES em que trabalhavam no momento da pesquisa, isto é, após a conclusão do curso, $40 \%$ (18) permaneciam na IES investigada, e os demais se encontravam atuando nas Instituições localizadas nas cidades já citadas, o que indica que a maioria permaneceu nas mesmas instituições em que se encontrava durante o curso.

No que respeita à idade no momento da titulação, os dados encontram-se a seguir.

Tabela 01 - Faixa etária dos egressos pesquisados no momento da titulação no Mestrado

\begin{tabular}{c|c|c}
\hline \hline Idade & Quantidade & Percentual \\
\hline 26 a 30 anos & 5 & $11 \%$ \\
\hline 31 a 35 anos & 4 & $9 \%$ \\
\hline 36 a 40 anos & 8 & $30 \%$ \\
\hline 41 a 45 anos & 13 & $18 \%$ \\
\hline 46 a 50 anos & 8 & $11 \%$ \\
\hline 51 a 55 anos & 5 & $3 \%$ \\
\hline 61 anos ou mais & 1 & $100 \%$ \\
\hline TOTAL & 44 & \\
\hline \hline
\end{tabular}

Fonte: Elaborado pelas autoras com base em dados da pesquisa

A maior procura pela titulação de Mestre em Educação ocorreu na faixa etária de 41 aos 45 anos, sendo a média das idades igual a 42 anos, aproximadamente. Isso revela que a PósGraduação não ocorreu logo após o término da graduação, que, geralmente, acontece na faixa de idade entre 20 e 25 anos, para aqueles que não interrompem os estudos. Evidencia, também, que as pessoas, ao buscarem o curso de Mestrado, já possuem vivências e experiências na área, indo à procura de aprofundamento de conhecimentos e aprimoramento profissional. No mesmo sentido, tem-se os dados referentes ao ano de conclusão da Graduação. 
Tabela 02 - Ano de conclusão da Graduação dos egressos participantes

\begin{tabular}{c|c|c}
\hline \hline Período & Número de concluintes & Percentual de concluintes \\
\hline De 1970 a 1980 & 3 & $7 \%$ \\
\hline De 1980 a 1990 & 13 & $30 \%$ \\
\hline De 1990 a 2000 & 10 & $23 \%$ \\
\hline De 2000 a 2010 & 16 & $36 \%$ \\
\hline De 2011 adiante & 1 & $2 \%$ \\
\hline Não responderam & 1 & $2 \%$ \\
\hline TOTAL & 44 & $100 \%$ \\
\hline
\end{tabular}

Fonte: Elaborado pelas autoras com base em dados da pesquisa

Observa-se que a maioria dos egressos pesquisados concluiu a graduação antes do ano 2000, com 60\%. Dos 44 participantes, apenas 6 (14\%) terminaram o Doutorado, e 5 deles, de 2010 a 2015.

Uma inferência que pode ser levantada, a partir dos dados referentes à idade, ao ano de conclusão da graduação e à localização das IES em que os participantes trabalhavam, é que a existência de mais um PPGE na região oportunizou a formação continuada desses profissionais na pós-graduação, pois, anteriormente ao PPGE da IES pesquisada, havia apenas o PPGE/UFU, bastante concorrido. Acrescenta-se a isso que há, atualmente, uma maior exigência institucional para a qualificação em nível pós-graduado stricto sensu.

Sobre a formação na graduação, 68\% (30) dos egressos possuem a formação em Licenciaturas, e 32\%, possuem graduação em nível de bacharelado. Constata-se que os egressos possuem Graduação em diversas áreas, mas, ao escolherem ingressar na pós-graduação em educação, interessam-se por esse campo científico, buscando melhor qualificação e formação profissional.

Gráfico 01 - Natureza da instituição de formação na graduação dos egressos pesquisados

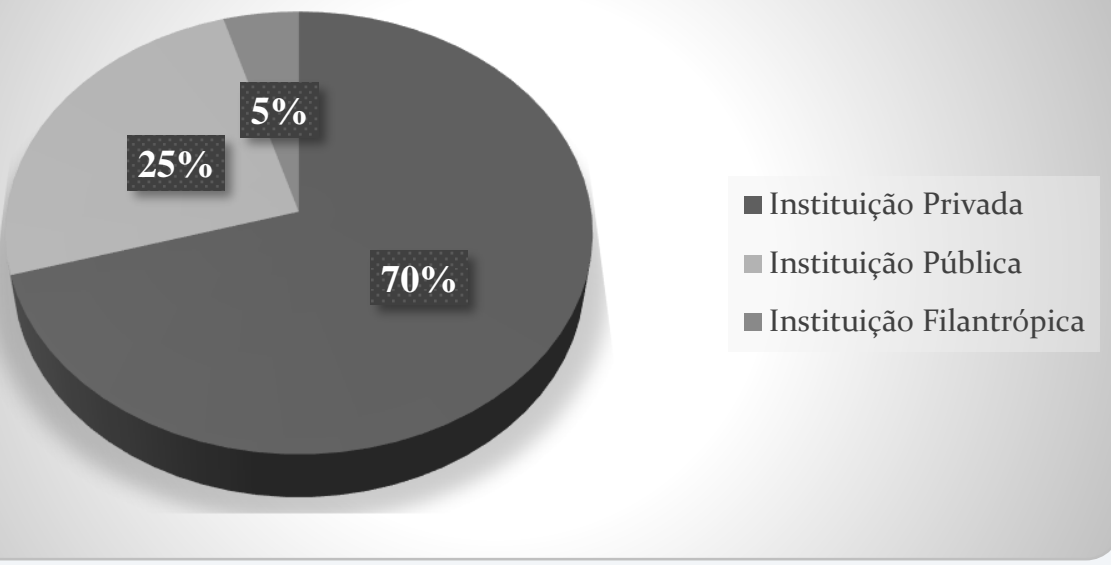

Fonte: Elaborado pelas autoras com base em dados da pesquisa 
A maioria dos participantes, 70\% (31), é oriunda de instituições privadas. Esses dados referentes às Instituições de formação dos participantes da pesquisa na graduação revelam que os egressos continuaram em instituições privadas, desde a sua formação inicial até em nível de mestrado. Além disso, a maioria deles, com 65\% (29), atua em instituições privadas. Uma das hipóteses para essa constatação é que a maior parte dos egressos tem origem nas regiões do Triângulo Mineiro e Alto Paranaíba, onde o número de instituições privadas é maior do que os de instituições públicas, que tiveram uma ampliação apenas nos últimos anos (a partir de 2007, com o REUNI).

Sobre a atividade profissional, na docência, entendida como ministrar aulas, atuar em órgãos ligados à Educação e fazer a gestão escolar, os dados encontram-se a seguir.

Tabela 03 - Atividades exercidas pelos egressos pesquisados na docência

\begin{tabular}{c|c|c|c|c|c|c}
\hline \multirow{2}{*}{ Especificação } & \multicolumn{2}{|c|}{ Antes do Mestrado } & \multicolumn{2}{c}{ Depois do Mestrado } & \multicolumn{2}{c}{ Atualmente (2017) } \\
\cline { 2 - 7 } & $\mathbf{N}^{\circ}$ & $\mathbf{\%}^{*}$ & $\mathbf{\mathbf { N } ^ { \circ }}$ & $\mathbf{\%}^{*}$ & $\mathbf{N}^{\circ}$ & $\mathbf{\%}^{*}$ \\
\hline Ministrando aulas & 38 & 86 & 39 & 89 & 40 & 91 \\
\hline $\begin{array}{c}\text { Atuando em órgãos da } \\
\text { Educação }\end{array}$ & 11 & 25 & 10 & 22 & 10 & 22 \\
\hline Gestão escolar & 13 & 30 & 12 & 27 & 10 & 22 \\
\hline Não responderam & 2 & 4 & 2 & 4 & 2 & 4 \\
\hline \hline
\end{tabular}

Fonte: Elaborado pelas autoras com base em dados da pesquisa

Nota:

*O total dos percentuais ultrapassa cem por cento, porque há elementos comuns nos tipos de atividades.

Verifica-se, de acordo com as respostas, que a maioria (86\%) dos egressos exercia a docência, ministrando aulas no ensino superior, antes de cursar o Mestrado, e continua a exercêla atualmente (89\%). Como se pode perceber, o percentual de respostas teve um aumento, caracterizando que os egressos que já estavam em sala de aula continuaram e outros, também, aderiram a essa atividade profissional após a conclusão do curso e permanecem até hoje. Isso significa que, de fato, o curso de mestrado tem forte vínculo com a docência, enquanto atuação no ensino. 
Gráfico 02 - Tempo de atuação, na docência, dos egressos pesquisados

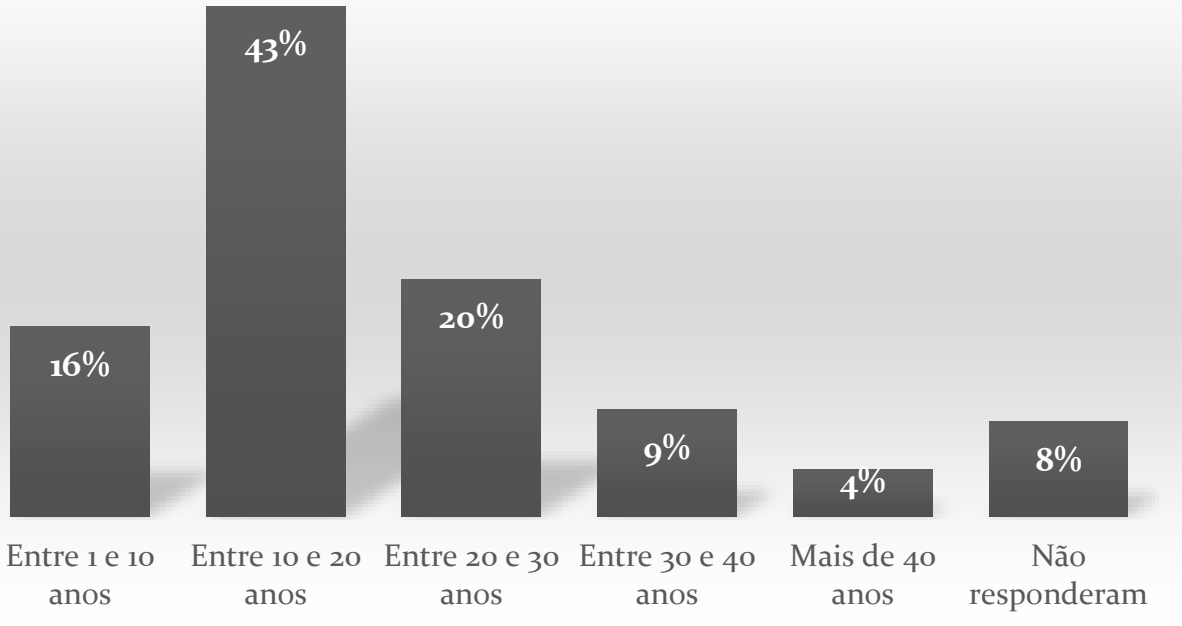

Fonte: Elaborado pelas autoras com base em dados da pesquisa

Os dados mostram, segundo Marcelo Garcia (1999), ao tratar dos ciclos vitais dos professores, com base em estudos de Huberman (1990), que a maioria dos egressos está numa fase de "diversificação e de ativismo", entre 10 e 30 anos (63\%). Nesta fase, podem ocorrer: a busca por melhoria de sua capacidade como docente, a procura por promoção profissional, e, ainda, redução das atividades docentes e o exercício paralelo de outras atividades, ou, até mesmo, o abandono. Os professores pesquisados se enquadram mais no primeiro grupo dessa fase, pois, ainda, estão se preocupando com o seu desenvolvimento profissional, investindo num curso de pós-graduação. No grupo pesquisado há, ainda, $16 \%$ em fase de "entrada ou de estabilização”, entre 1 e 10 anos. Na de entrada (1 a 3 anos), há períodos de sobrevivência diante do choque de realidade e de descoberta, seguida de um período de estabilização (4 a 6 anos) em que o professor se sente mais independente e integrado. Outro grupo (13\%), encontra-se na fase de "serenidade e de conservadorismo", acima de 30 anos, que consiste na busca de estabilidade profissional.

Um dos objetivos da pós-graduação stricto sensu é a formação do pesquisador. Nesse sentido, uma das perguntas se referia à participação em projetos de pesquisa, após a conclusão do mestrado. Dos pesquisados, 61\% (27) responderam afirmativamente. Dentro desse total de 27 que participaram, considerando que as pessoas assinalaram mais de uma alternativa: $33 \%$ (9) participaram como coordenadores, $48 \%$ (13) como colaboradores e 66\% (18) como membros da equipe. $\mathrm{O}$ número dos que não participaram de projetos de pesquisa após o mestrado 39\% (17), e os que participam como colaboradores $48 \%$ (13) é significativo e permite inferir que, embora os cursos de pós-graduação tenham a formação para a pesquisa como um 
dos seus objetivos, nem todos se dedicam a essa atividade. Muitos acabam se envolvendo exclusivamente com as atividades de ensino por diversos motivos, dentre eles, tempo, oportunidades e falta de incentivo.

$\mathrm{Na}$ entrevista, esse questionamento foi retomado e, do total de oito entrevistados, dois responderam que participam de atividades de pesquisa diariamente, em virtude da atuação em coordenação de grupo de pesquisa e supervisão na Pós-Graduação. Os demais alegaram falta de incentivo institucional e falta de tempo para se dedicar à pesquisa, conforme se pode observar, pela transcrição da fala dos entrevistados ${ }^{2}$ :

Atualmente não participo de atividade de pesquisa. Nós tínhamos um grupo de pesquisa, mas estamos parados por determinações superiores, mas o que dificulta procurar outro grupo, fora da Instituição, é o tempo. (EGRESSO 13).

Como eu trabalho na Universidade, aqui não tem grupo de pesquisa, mas eu dedico, quando posso, a pesquisa com os alunos de TCC e também da iniciação científica. (EGRESSO 18).

Até pouco tempo ainda participava do grupo, mas tive que parar por causa de outras atividades. (EGRESSO 07).

Mas o fato de não participar mais intensamente desse grupo de pesquisa é tempo. O tempo é a dificuldade das Universidades Privadas. A dificuldade é professor com tempo para dedicar à pesquisa. (EGRESSO 05).

Com relação à publicação de artigos, 64\% (28) dos egressos responderam positivamente, sendo que 54\% deles de um a cinco artigos. Esses números são próximos dos que participaram de atividade de pesquisa, o que corrobora a constatação de que muitos concluem o mestrado e não se dedicam às atividades de pesquisa, embora continuem a atuar no ensino superior. Constatou-se, também, que $68 \%$ (30) dos egressos pesquisados publicaram capítulos ou livros na área da Educação, após a conclusão do curso.

Questionados se participavam de eventos científicos da área da Educação, 80\% (35) responderam que "sim e sempre". "Sim e raramente" 20\% (9). Dentre os 35 que responderam "sim e sempre", 68\% (24) foram como ouvintes. Esse dado confirma que nem todos se dedicam à atividade de pesquisa, mesmo no ensino, pois, se isso ocorresse, haveria maior possibilidade de participação com apresentação de trabalhos.

\footnotetext{
2 Para preservar a confidencialidade dos dados colhidos e a privacidade dos envolvidos, utilizou-se, para identificação dos sujeitos, a nomenclatura Egresso, seguida de um número, que varia de 1 a 44, sendo esta também a numeração utilizada para as entrevistas.
} 


\section{O mestrado em educação: motivações e condições}

Estimulados a elencar as motivações que os levaram a ingressar no PPGE investigado, os participantes, por meio de questionário e entrevista, apontaram diferentes razões. Em uma das questões do questionário, os egressos participantes da pesquisa deveriam assinalar no máximo três opções referentes às principais motivações para ingressar no Mestrado em Educação, numerando-as de 1 (como sendo a mais importante) a 3 (menos importante).

Tabela 04 - Motivações para ingresso no Mestrado em Educação na IES pesquisada

\begin{tabular}{|c|c|c|c|c|c|c|}
\hline \multirow{2}{*}{ Especificação } & \multicolumn{4}{|c|}{ Grau de importância } & \multirow{2}{*}{ Total } & \multirow{2}{*}{$\begin{array}{c}\% \text { do total de } \\
\text { respondentes }(44)\end{array}$} \\
\hline & 1 & 2 & 3 & $\begin{array}{c}\text { Não } \\
\text { especificado }^{1}\end{array}$ & & \\
\hline $\begin{array}{l}\text { Complementação ao } \\
\text { curso de graduação }\end{array}$ & 0 & 3 & 4 & 2 & 9 & 20,4 \\
\hline $\begin{array}{l}\text { Finalidade de ascensão } \\
\text { na carreira docente }\end{array}$ & 10 & 4 & 4 & 6 & 24 & 54,5 \\
\hline $\begin{array}{l}\text { Necessidade de } \\
\text { aprimoramento de } \\
\text { conhecimento }\end{array}$ & 8 & 8 & 4 & 8 & 28 & 63,6 \\
\hline $\begin{array}{l}\text { Conhecimento } \\
\text { pedagógico }\end{array}$ & 0 & 5 & 4 & 4 & 13 & 29,5 \\
\hline $\begin{array}{l}\text { Melhor qualificação para } \\
\text { o mercado de trabalho }\end{array}$ & 4 & 3 & 5 & 5 & 17 & 38,6 \\
\hline $\begin{array}{l}\text { Interesse em realizar } \\
\text { pesquisa }\end{array}$ & 3 & 7 & 5 & 5 & 20 & 45,5 \\
\hline Status & 0 & 0 & 1 & 0 & 1 & 2,3 \\
\hline $\begin{array}{l}\text { Possibilidade de melhor } \\
\text { emprego }\end{array}$ & 1 & 2 & 1 & 1 & 5 & 11,4 \\
\hline Progressão salarial & 3 & 3 & 5 & 2 & 13 & 29,5 \\
\hline Interesse pessoal & 5 & 2 & 2 & 1 & 10 & 22,7 \\
\hline $\begin{array}{l}\text { Melhores práticas de } \\
\text { ensino }\end{array}$ & 3 & 0 & 4 & 5 & 12 & 27,3 \\
\hline \multicolumn{5}{|l|}{ TOTAL } & 153 & \\
\hline
\end{tabular}

Fonte: Elaborado pela autora com base em dados da pesquisa

1 "Não especificado" refere-se a respostas dadas sem a atribuição de grau de importância, ou seja, o respondente apenas assinalou a alternativa.

Observando a totalidade das respostas para cada categoria, as mais frequentes foram: necessidade de aprimoramento de conhecimento, marcada por $63,6 \%$ dos respondentes, sendo a segunda, dentre as "mais importantes"; finalidade de ascensão na carreira docente, para 
$54,5 \%$ dos respondentes, tendo sido a alternativa assinalada com o maior grau de importância; interesse em realizar pesquisa, por 45,5\% dos respondentes, porém pouco assinalada (por 3 respondentes) como a mais importante; e melhor qualificação para o mercado de trabalho, $38,6 \%$ dos respondentes, sendo a mais importante para 4 respondentes. Com pequeno percentual aparecem: status e possibilidade de melhor emprego.

Pode-se observar que, ao mesmo tempo em que o participante procura aprimoramento de conhecimento, incluindo o conhecimento pedagógico e a formação para a pesquisa, ele tem motivações que apontam para a profissionalização, ou seja, a ascensão na carreira, a qualificação para o mercado de trabalho e a progressão salarial, ainda que a possibilidade de melhor emprego tenha sido pouco assinalada. Esse último dado é coerente com aquele que revela que a maioria permaneceu nas instituições em que atuava ao iniciar o curso, instituições privadas.

Acerca das motivações, afirma Cunha (2010, p. 181):

As motivações nem sempre pressupõem processos sistemáticos de reflexão prévia. Envolvem intuições e representações de cada sujeito. São, entretanto, produzidas numa teia de condições que estimulam a opção dos sujeitos. Diferentes fatores se imbricam e resultam em uma tomada de decisão que interfere na trajetória de formação de cada docente.

Portanto, segundo Cunha, as motivações de cada indivíduo englobam uma teia de fatores e condições, além de serem marcadas por as representações de cada sujeito, nem sempre resultando, de processos sistemáticos de decisão.

Do mesmo modo que a motivação ligada à progressão salarial é elencada no questionário, esta também é citada na entrevista, como um dos motivos para ingressar ao Programa, conforme nos fala o Egresso 21: “A minha motivação foi principalmente a questão da formação em termos de currículo e a minha progressão, porque assim, eu conseguiria a progressão vertical com a titulação” (EGRESSO 21).

Nas entrevistas, percebe-se que os egressos também citam a proximidade da IES em relação ao local de moradia, ou seja, o fato de não precisar viajar com frequência, como uma das motivações para ingresso no Mestrado:

A escolha pelo Mestrado primeiramente foi pela facilidade de estar na minha cidade, não ter que viajar ou pegar estrada toda semana. Esse foi um ponto essencial. (EGRESSO 13).

A minha maior dificuldade eram as viagens e porque ficava impossibilitava de fazer viagens para cursar o Mestrado. E assim que surgiu a oportunidade aqui, eu tentei agarrar com unhas e dentes. (EGRESSO 32). 
Para Cunha, em sua pesquisa, a dificuldade de afastamento pleno do trabalho, ligada à oferta de cursos em suas cidades, "são, porém, argumentos complementares, que se aliaram às razões sustentadas em motivações mais consequentes". (CUNHA, 2010, p. 180).

Diante da necessidade de formação docente, o ingresso na Pós-Graduação stricto sensu em Educação é uma opção de aprimoramento para a docência. Assim, "ao mesmo tempo em que cumpre o processo de formação valorizado na carreira docente, atingindo o grau de mestre e/ou doutor, encontra possibilidades de cumprir sua necessidade de conhecimentos ligados à sua condição docente". (CUNHA, 2010, p. 176). Portanto, a procura pelos cursos de PósGraduação stricto sensu em Educação por profissionais de diferentes áreas profissionais tem o objetivo de formação de professores e a melhoria na carreira docente, porque

[...] a formação da base profissional não é suficiente para o enfrentamento dos desafios da docência. Percebem-se portadores de uma competência parcial e entendem que a Pós-graduação em Educação pode ser o espaço que contribui com a sua condição de professor. (CUNHA, 2010, p. 179).

As condições para fazer o mestrado, incentivos e tempo de dedicação, encontram-se abaixo (Gráfico 03)

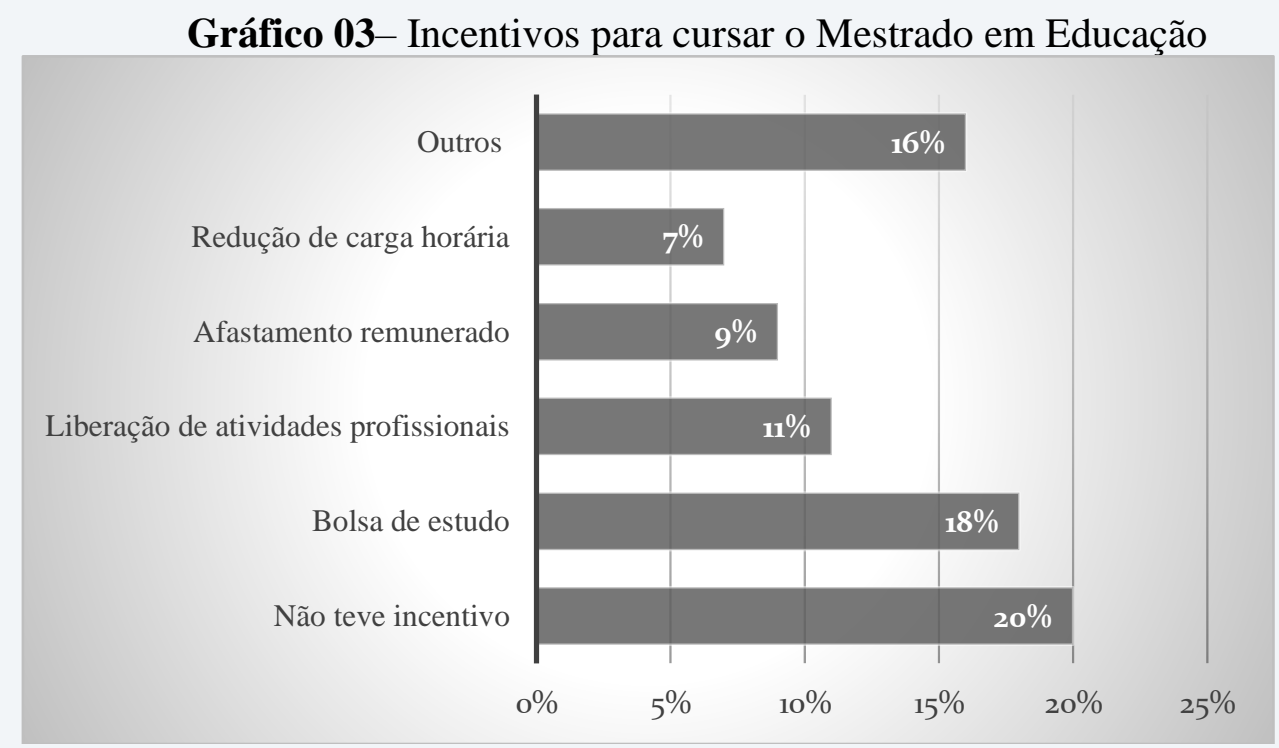

Fonte: Elaborado pela autora com base em dados da pesquisa

Observa-se que poucos participantes tiveram a concessão de bolsa de estudo, 18\% (8) dos alunos, sendo essas bolsas destinadas pela CAPES ou FAPEMIG. Assim, como poucos, 11\% (5), tiveram a liberação das atividades profissionais durante o período do Mestrado, e, apenas, 9\% (4) foram beneficiados com o afastamento remunerado. E 16\% (7) tiveram outros tipos de 
incentivo, como adequação ao horário das aulas, horário especial para trabalhar e, também, descontos nas mensalidades. Além disso, verifica-se que $82 \%$ dos egressos participantes tiveram tempo parcial para se dedicarem ao curso, conciliando trabalho e estudo. Esses números permitem constatar que egressos do Mestrado na IES pesquisada tiveram poucos ou nenhum incentivo externo para a realização do curso, a maioria teve que trabalhar para custear os seus estudos.

\section{Contribuições do mestrado em educação}

Em relação às contribuições do PPGE da IES pesquisada para os egressos, ao responder uma das questões do questionário, os participantes da pesquisa deveriam assinalar no máximo 3 opções, numerando-as de 1 (como sendo a mais importante) a 3 (menos importante).

Tabela 05 - Contribuições do Mestrado para os egressos pesquisados

\begin{tabular}{|c|c|c|c|c|c|c|}
\hline \multirow{2}{*}{ Especificação } & \multicolumn{4}{|c|}{ Grau de importância } & \multirow[b]{2}{*}{ Total } & \multirow{2}{*}{$\begin{array}{l}\text { \% do total de } \\
\text { respondentes } \\
\text { (44) }\end{array}$} \\
\hline & 1 & 2 & 3 & $\begin{array}{c}\text { Não } \\
\text { especificado } 1\end{array}$ & & \\
\hline $\begin{array}{l}\text { Aprofundamento de } \\
\text { conhecimento }\end{array}$ & 17 & 8 & 6 & 5 & 36 & 82 \\
\hline $\begin{array}{l}\text { Melhor desempenho na } \\
\text { carreira docente }\end{array}$ & 3 & 10 & 3 & 1 & 17 & 39 \\
\hline $\begin{array}{l}\text { Aprimoramento } \\
\text { profissional }\end{array}$ & 3 & 4 & 8 & 1 & 16 & 36 \\
\hline $\begin{array}{l}\text { Melhora na capacidade } \\
\text { de empregabilidade }\end{array}$ & 1 & 1 & 1 & 1 & 4 & 9 \\
\hline $\begin{array}{lll}\text { Aumento de salário e } \\
\text { melhoria na condição } \\
\text { de vida }\end{array}$ & 5 & 3 & 4 & 1 & 13 & 29 \\
\hline $\begin{array}{l}\text { Ascensão de cargo e } \\
\text { novo status social }\end{array}$ & 1 & 0 & 3 & 0 & 4 & 9 \\
\hline $\begin{array}{l}\text { Melhoria da prática } \\
\text { pedagógica }\end{array}$ & 3 & 9 & 5 & 3 & 20 & 45 \\
\hline $\begin{array}{l}\text { Preparação para a } \\
\text { atividade de pesquisa }\end{array}$ & 7 & 7 & 12 & 4 & 30 & 68 \\
\hline TOTAL & & & & & 140 & \\
\hline
\end{tabular}

Fonte: Elaborado pela autora com base em dados da pesquisa

"Não especificado" refere-se às respostas dadas sem a atribuição de grau de importância, ou seja, o respondente apenas assinalou a alternativa.

As categorias, que aparecem com maior frequência, são as referentes à formação: aprofundamento de conhecimento (82\% dos respondentes), preparação para a atividade de 
pesquisa (68\% dos respondentes), e melhoria da prática pedagógica (45\% dos respondentes). Esses resultados permitem afirmar que os objetivos do Programa estão sendo atingidos - a formação do docente e do pesquisador, com predominância da formação para a docência.

Constata-se, entretanto, que, o aluno entra no curso com uma motivação e finaliza com uma contribuição diferente, pois a melhoria na carreira e o aumento de salários não foram as contribuições mais assinaladas. A contribuição mais importante para os egressos foi o aprofundamento de conhecimento, que pode ser científico e/ou pedagógico, tendo sido marcada com o número 1 (a mais importante), por 17 dos respondentes. A preparação para a atividade de pesquisa tem percentual de $68 \%$ do total de respondentes, mas cai para o grau de importância 3, provavelmente em razão das dificuldades e limitações para essa atividade, como a falta de tempo mencionada pelos egressos, e por falta de incentivo das IES.

Em relação às dimensões de desenvolvimento profissional docente, o desenvolvimento pedagógico, o conhecimento e a compreensão de si mesmo, o desenvolvimento cognitivo, o desenvolvimento teórico, e o desenvolvimento da carreira, conforme proposto por Marcelo Garcia (1999), os participantes, quando instados a falar sobre o como o mestrado contribuiu para esse desenvolvimento, alguns destacam que é difícil separar essas dimensões, como se constata nessas falas:

A contribuição do mestrado está envolvendo todas as áreas na mesma intensidade, porque, o pedagógico, a compreensão de si mesmo, o cognitivo e o teórico estão ligados e nós dependemos um do outro, para que ocorra a aprendizagem. Acho que todos contribuíram da mesma forma. (EGRESSO 18).

Sobre isso, Cunha (2010) afirma que todas essas dimensões internas do desenvolvimento profissional estão interligadas, não havendo como considerá-las de maneira individual.

Poderíamos dizer que o desenvolvimento profissional do professor, nessa perspectiva, não é apenas o desenvolvimento pedagógico, o conhecimento e a compreensão de si mesmo, o desenvolvimento cognitivo ou teórico, mas tudo isso, ao mesmo tempo, delimitado ou incrementado por uma situação profissional que permite ou impede o desenvolvimento de uma carreira docente. (CUNHA, 2010, p. 193).

Entretanto, alguns entrevistados destacam um ou outro aspecto, ora o pedagógico, ora o teórico, conforme se pode averiguar em seus depoimentos:

Como eu vinha de uma linha muito tecnicista, o Mestrado me fez ver o outro lado, o lado pedagógico. Ele me fez ver a essência do professor. Então, ele me fez ver a importância desse lado do conhecimento da teoria. (EGRESSO 07). 
Teoricamente, eu descobri coisas que na nossa formação não tinha tempo para isso, e a prática também traz um cotidiano que te absorve. Então eu tive oportunidades de fazer leituras que eu utilizo até hoje. Foi muito enriquecedor esse processo de formação no Mestrado". (EGRESSO 32)

A pesquisa é considerada uma contribuição importante para alguns dos egressos, conforme as próprias descrições de trechos das entrevistas:

Contribuiu com minha forma de fazer pesquisa. (EGRESSO 15).

Eu acho que o segredo, o grande "pulo do gato" do mestrado é você aprender essa questão da iniciação à pesquisa. Você conseguir fazer pesquisa individualmente, porque uma coisa é você ser aluno de iniciação, é você participar do grupo de pesquisa, e outra coisa é você ter que ser a cabeça pensante na pesquisa. (EGRESSO 07).

O mestrado é uma forma de aprimorar a nossa visão como pesquisador. Eu acho que nesse ponto o Mestrado contribui muito com esse novo olhar. Eu aprendi muito a olhar para o campo da pesquisa, que é uma área que me atrai muito. (EGRESSO 18).

Acerca dos fatores que têm dificultado o desenvolvimento profissional, aparece como principal o tempo para a dedicação aos estudos e à pesquisa. Ainda sobre as dificuldades, houve menção à ausência de incentivo institucional. Essas dificuldades, certamente, contribuem para o fato de que a maioria não tenha dado continuidade à formação pós-graduada, ingressando em um curso de doutorado, como se pode verificar no gráfico abaixo.

Gráfico 04 - Situação dos egressos em relação ao doutorado

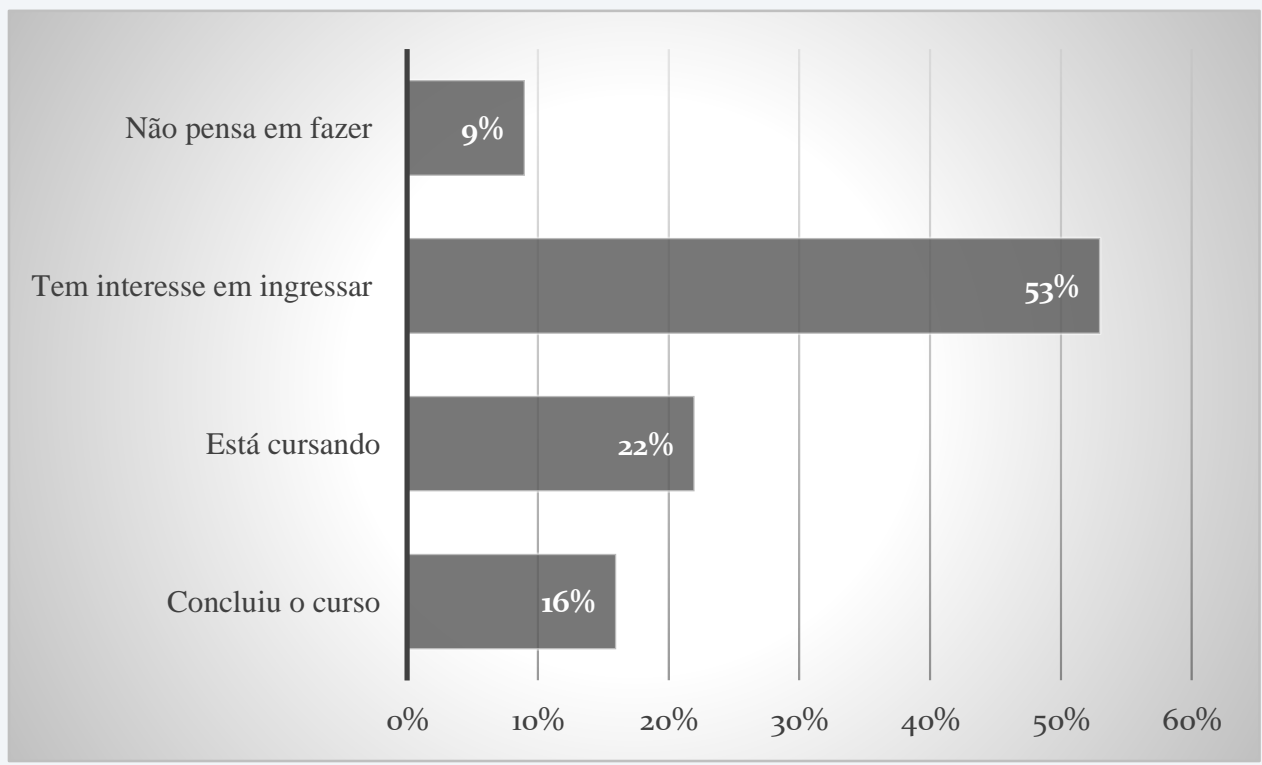

Fonte: Elaborado pela autora com base em dados da pesquisa 
Os números confirmam que a maioria não deu continuidade à formação em curso de Doutorado, mas tem interesse de fazê-lo, o que é um sinal positivo. Cabe ponderar que, além das dificuldades mencionadas anteriormente, na região do Triângulo Mineiro e Alto Paranaíba, só existia o curso de Doutorado na UFU, até 2015, quando foi autorizado esse curso na UNIUBE.

\section{Em síntese}

A Pós-Graduação em Educação é uma grande área, pelo número de cursos e Programas e pelas contribuições que tem trazido para a educação brasileira, de modo especial para o desenvolvimento profissional docente, apesar dos desafios e das contradições que permeiam o movimento dessa área no contexto histórico, social e político de nosso país.

A partir dos dados mostrados e analisados neste artigo sobre o perfil do egresso do PPGE da IES pesquisada, as suas motivações em relação ao mestrado, e as contribuições deste para a sua formação, é possível constatar que esse Programa de Pós-Graduação em Educação, regional, localizado no interior do país, cumpre um importante papel no desenvolvimento profissional de docentes do ensino superior, pois lhes oportuniza o acesso à formação pósgraduada, dentro das suas condições objetivas de vida e de trabalho.

Em sua maioria, os egressos construíram a sua trajetória de formação e de atuação em instituições privadas de ensino superior. Têm a necessidade de aprimoramento profissional e o desejo de ascensão na carreira, motivos principais para a busca de um curso de mestrado, porém poucos contam com bolsas de estudo, com a liberação das atividades profissionais ou redução de carga horária para a realização do curso. Ainda que haja a necessidade de formação pósgraduada, mestrado e doutorado, para o exercício da docência no ensino superior, essas instituições poucos incentivos oferecem. Cabe ao professor enfrentar os desafios e o ônus de sua formação.

Em relação aos objetivos do curso de mestrado do PPGE da IES, as contribuições pendem mais para a docência do que para a pesquisa, com o aprofundamento de conhecimentos e a melhoria da prática pedagógica. Embora afirmem que o curso prepara para a pesquisa, as condições para a continuidade dessa atividade não são as mais favoráveis - falta tempo, faltam incentivos institucionais e oportunidades de participação em grupos de pesquisa, assim como poucas possibilidades de realização do doutorado, embora haja a intenção, manifestada por grande parte deles. 
É nesse contexto de conquistas, de desafios e de contradições que os egressos do PPGE da IES investigada avaliam as contribuições do curso de mestrado, mostrando que ele contribuiu positivamente para o seu desenvolvimento profissional, o que impacta consequentemente na qualificação do professor para as instituições de ensino superior da região.

\section{REFERÊNCIAS}

ARAÚJO, Monica Lopes Folena; ARAÚJO, Maria Inêz Oliveira. Como formar professores? concepções de pós-graduandos em educação. Práxis Educacional, [S.1.], v. 15, n. 31, p. 366388, jan. 2019. ISSN 2178-2679. Disponível em:

<http://periodicos2.uesb.br/index.php/praxis/article/view/4678>. Acesso em: $06 \mathrm{dez}$. 2019..

BRASIL. Lei n. 4.024/61, de 20 de dezembro de 1961. Fixa as diretrizes e bases da Educação Nacional. Brasília: 1961. Disponível em:

http://presrepublica.jusbrasil.com.br/legislacao/108164/lei-de-diretrizes-e-base-de-1961-lei4024-61. Acesso em: 18 jun. 2016.

BRASIL. Parecer n. 977/65, de 03 de dezembro de 1965. Brasília: 1965. Disponível em: https://www.capes.gov.br/images/stories/download/459legislação/Parecer_CESU_977_1965. pdf. Acesso em: 18 jun. 2016.

BRASIL. Lei no 9.394, de 20 de dezembro de 1996. Estabelece as diretrizes e bases da Educação Nacional. Disponível em:

http://www.planalto.gov.br/ccivil_03/LEIS/L9394.htm.Acesso em: 18 jun. 2016

CUNHA, Maria Isabel da. Lugares de formação: tensões entre a academia e o trabalho docente. XV ENDIPE. Belo Horizonte, 2010. Disponível em:

http://www.scielo.br/scielo.php?script=sci_nlinks\&ref=000148\&pid=S1414-

3283201100040000500006\&lng=pt. Acesso em: 22 mar. 2017.

CURY, Carlos Roberto Jamil. Quadragésimo ano do parecer CFE n. 977/65. Revista

Brasileira de Educação, n. 30, p. 7-20, número especial, set./dez. 2005

GRAY, David E. Pesquisa no mundo real. Trad. Roberto Cataldo Costa. 2. ed. Porto Alegre: Penso, 2012.

IBIAPINA, Ivana Maria Lopes de Melo. Pesquisa colaborativa: investigação, formação e produção de conhecimentos. Brasília: Líber Livro Editora, 2004.

MARCELO GARCÍA, Carlos. Formação de professores para uma mudança educativa. Portugal: Porto Editora, 1999.

MINAYO, Maria Cecília de Souza; DESLANDES, Suely Ferreira; GOMES, Romeu.

Pesquisa social. Teoria, método e criatividade. Rio de Janeiro: Vozes, 2015. 
PLACCO, Vera Maria Nigro de Souza; SOUZA, Vera Lucia Trevisan de. (Org). Aprendizagem do adulto professor. São Paulo: Loyola, 2014.

SANTOS, Ana Lúcia Félix dos; AZEVEDO, Janete Maria Lins de. A pós-graduação no Brasil, a pesquisa em educação e os estudos sobre a política educacional: os contornos da constituição de um campo acadêmico. Revista Brasileira de Educação, v. 14, n. 42, set./dez. 2009. Disponível em: http://www.scielo.br/pdf/rbedu/v14n42/v14n42a10.pdf. Acesso em: 21 nov. 2016.

SEVERINO, Antonio Joaquim. In: FERREIRA, Naura Syria Carapeto (Org.). A avaliação no PNPG 2005-2010 e a política de pós-graduação no Brasil. Políticas públicas e gestão da educação: polêmicas, fundamentos e análises. Brasília: Líber Livro, 2006.

SEVERINO, Antonio Joaquim. Docência universitária: a pesquisa como princípio pedagógico. Revista @mbienteeducação, São Paulo, v. 2, n.1, p. 120-128, jan./jul. 2009.

SOARES, Sandra Regina; CUNHA, Maria Isabel da. Formação do professor: a docência universitária em busca da legitimidade. Salvador: EDUFBA, 2010.

\section{SOBRE AS AUTORAS:}

\section{Susély Aparecida Fonseca Gonçalves}

Mestre em educação pela Universidade de Uberaba (UNIUBE). Aluna do Doutorado em Educação da UNIUBE. Pertence ao Grupo de Pesquisa Desenvolvimento profissional e trabalho docente na contemporaneidade. E-mail: suselyfonseca@yahoo.com.br

iD http://orcid.org/0000-0001-8236-0453

\section{Marilene Ribeiro Resende}

Doutora em Educação Matemática pela Pontifícia Universidade Católica de São Paulo (PUC/SP), docente permanente do Programa de Pós-Graduação em Educação da Universidade de Uberaba (UNIUBE), Uberaba/MG. Editora da Revista Profissão Docente. Membro dos seguintes Grupos de Pesquisa: Desenvolvimento profissional e trabalho docente na contemporaneidade; Desenvolvimento profissional docente e representações sociais (GDEPRES); Grupo de estudos e pesquisas em instrução, desenvolvimento e educação (GEPIDE); Grupo de pesquisa em educação algébrica. E-mail: marilene.resende@ uol.com.br iD http://orcid.org/0000-0002-6740-1787 